\title{
The prevalence of renal anaemia in new dialysis patients before and after routine eGFR reporting: A single centre experience*
}

\author{
Senyo K. Tagboto, Liz Cropper \\ University Hospital of North Staffordshire, Stoke-on-Trent, UK \\ Email: Senyo2@hotmail.com, Liz.Cropper@uhns.nhs.uk
}

Received 20 November 2011; revised 30 January 2012; accepted 20 February 2012

\begin{abstract}
Background: In March 2006, evidence-based guidelines for the management of chronic kidney disease (CKD) in adults in the UK were published including the recommendation that kidney function should be assessed by formula-based estimation of glomerular filtration rate (eGFR), using the 4-variable modification of diet in renal disease (MDRD) equation. The purpose of this study was to evaluate whether or not improved assessment of renal function by eGFR reporting followed by an intensive local education programme and local protocols affected the prevalence of renal anaemia at the time of starting dialysis for the first time. Methods: To do this, we collected data on haemoglobin levels in people starting renal replacement therapy (RRT) for the first time, during the $\mathbf{1 2}$ months immediately preceding eGFR reporting. We collected data for a further 12 months after eGFR was introduced; starting 6 months after the official date of introduction. Results: The proportion of people with Haemoglobin $(\mathrm{Hb})$ levels $\geq 11 \mathrm{~g} / \mathrm{dl}$ increased from $25.4 \%$ in the pre-eGFR era to $41.1 \%$ in the post eGFR era. In addition, average $\mathrm{Hb}$ levels were better in the post eGFR era $(9.89 \mathrm{vs} .10 .2 \mathrm{~g} / \mathrm{dl})$ although this did not reach statistically significance. In general, in the post eGFR era, people known to the renal services for less than 1 month prior to starting RRT had the worst $\mathrm{Hb}$ levels $(8.7 \mathrm{~g} / \mathrm{dl})$. $\mathrm{Hb}$ levels were higher according to time of referral prior to RRT with peak Hb levels in people referred 6 - 9 months $(11.5 \mathrm{~g} / \mathrm{dl})$ beforehand. Conclusions: It has been suggested that estimated GFR reporting may be associated with earlier recognition of kidney disease. This may have contributed to the increase in the proportion of people with optimal haemoglobin $(\geq 11 \mathrm{~g} / \mathrm{dl})$ levels prior to starting renal replacement therapy. However a
\end{abstract}

${ }^{*}$ Competing interests: The authors declare that they have no competing interests. large number still start renal replacement therapy with severe anaemia. The increase in $\mathrm{Hb}$ levels in the post eGFR era could also result from better anaemia care which could be an effect of other guideline implementation.

Keywords: Anaemia; Estimated Glomerular Filtration Rate; Haemodialysis; Peritoneal Dialysis; MDRD Equation

\section{BACKGROUND}

Measurements of the rate at which solutes in blood are filtered by the kidneys \{glomerular filtration rate (GFR)\} are the ideal method of evaluating renal function. These typically involve artificially injecting solutes such as inulin or the radioisotope chromium ${ }^{51}$ chelated with ethylenediaminetetraacetic acid (EDTA) and measuring the rate of filtration of these solutes. The manner in which endogenously produced solutes are removed by the kidney including creatinine and cystatin $\mathrm{C}$ may also be used to estimate GFR [1].

However these techniques are cumbersome and impractical in routine clinical practice. This has led to the proliferation of a number of mathematical formulas aimed at estimating this (eGFR) [2]. These are usually based on serum creatinine level, age, sex, and race. In children, these formulas tend to be based on height, length, weight and serum creatinine levels [3,4].

The most widely used method for adults is the 4variable modification of diet in renal disease (MDRD) equation, as it has proved robust and accurate [5].

In March 2006, evidence-based guidelines for the management of chronic kidney disease (CKD) in adults in the UK were published. These guidelines included the recommendation that kidney function in patients with CKD should be assessed by formula-based estimation of glomerular filtration rate (eGFR), using the MDRD equation and that all clinical biochemistry laboratories in 
the country should report estimates of eGFR alongside measurements of serum creatinine [6].

At the same time, the classification of CKD into 5 stages based on the proposal by the US/DOQI group was adopted in the UK. These classified CKD based on the severity of renal dysfunction as follows: (CKD stage 1, GFR $>90 \mathrm{ml} / \mathrm{min} / 1.73 \mathrm{~m}^{2}$; CKD stage 2, GFR 60 - 89 $\mathrm{ml} / \mathrm{min} / 1.73 \mathrm{~m}^{2}$; CKD stage 3, GFR $30-59 \mathrm{ml} / \mathrm{min} /$ $1.73 \mathrm{~m}^{2}$; CKD stage 4 , GFR $15-29 \mathrm{ml} / \mathrm{min} / 1.73 \mathrm{~m}^{2}$; CKD stage 5 , GFR $<15 \mathrm{ml} / \mathrm{min} / 1.73 \mathrm{~m}^{2}$ or dialysis). These stages represent kidney disease with normal, mild, moderate, severe kidney dysfunction or kidney failure/dialysis respectively [7].

In the United Kingdom, a quality and outcomes framework has been introduced into primary care to systematically incentivize process measures such as computerization and chronic disease management by establishing practice-based disease registers. With respect to $\mathrm{CKD}$, general practitioners (GPs) were required to have a register of patients with CKD stages 3 - 5 and focus care towards limiting the progression of kidney disease in these patients based on local research findings and the wider international consensus. This has resulted in a paradigm shift from kidney disease being viewed as a secondary care condition to being a primary care priority. Kidney disease is now recognized as a public health problem in the United Kingdom and has become a priority area under the National Health Service [8].

The nephrology department at the University Hospital of North Staffordshire covers a population of 1.2 million people living in Staffordshire and parts of Shropshire and Cheshire. The department deals with 367 GP practices each with 1 - 17 GPs. We worked with the clinical biochemistry department to introduce eGFR reporting locally from the beginning of September 2006. This was preceded by a local conference at the end of August 2006 where the concepts were explained to GPs. Over the next 6 months, there were several additional educational activities for GPs and practice nurses. We used a combination of locally organised seminars, practice based lectures, interactive small-group workshops and information brochures. Local protocols for CKD management were introduced including improving contact with GPs by e-mail or telephone as a means of improving service delivery. Finally, we encouraged GPs to consider referring CKD patients with an eGFR of less than $30 \mathrm{mls} / \mathrm{min}$ to the service unless multiple co morbidities made it unlikely that those patients would benefit from dialysis.

The purpose of this study was to evaluate whether or not improved assessment of renal function by eGFR reporting followed by an intensive local education programme and local protocols affected the prevalence of renal anaemia at the time of starting dialysis for the first time.

\section{METHODS}

Data on people starting renal replacement therapy is routinely collected and stored on our database $\left(\right.$ Cyber $\left.\operatorname{Ren}^{\mathbb{B}}\right)$ for audit purposes.

We retrieved this data retrospectively, as part of our ongoing audit, on all patients starting renal replacement therapy (RRT) for the first time during the 12 months immediately preceding eGFR reporting (1st September 2005 to 31 st August 2006), and for a further 12 months after the introduction of eGFR reporting. We excluded the immediate 6 months post-reporting during time which local protocols, experience and expertise were being developed (i.e. 1st March 2007 to 28th February 2008). This data was thoroughly checked for accuracy. This research did not involve experimental research per se.

This included information on modality type including haemodialysis (HD), peritoneal dialysis (PD) and transplantation. Patients starting RRT elsewhere prior to transfer to our unit (including pre-emptive transplantation which is carried out elsewhere with patients transferred back after 10 days) were excluded. We collected demographic and the most recent laboratory data just prior to starting RRT (On the same day in most cases, but up to 3 weeks prior).

We also collected data on when patients were first seen by the renal services and the time between this and their first dialysis treatment. For the purposes of this paper we consider people starting dialysis within 3 months of being known to the renal services as starting dialysis without enough time for adequate preparation.

\section{RESULTS}

In the year prior to eGFR reporting, our Unit started 79 patients on RRT. An additional 13 people were started on RRT elsewhere and transferred into the programme. In the year starting 6 months after initial routine eGFR reporting, we started a total of 92 patients on RRT and a further 19 patients were started elsewhere and subsequently transferred to us. Pre-dialysis $\mathrm{Hb}$ levels were not available in 2 of the 92 patients.

Because of the difficulty getting reliable laboratory data on patients started on treatment elsewhere, further analysis was limited to people started on RRT locally in the year prior to eGFR reporting $(n=79)$ and in the year afterwards following the 6 months watershed period $(\mathrm{n}=$ 92).

Of the 79 people starting dialysis in the year prior to eGFR, 27 (34.2\%) were known to the renal services for less than 3 months prior to first dialysis and of the 92 people starting dialysis in the year after eGFR, 33 (35.9\%) were known to the service for less than 3 months. In this study, eGFR reporting did not appear to 
change the proportion of people starting dialysis without adequate preparation.

Excluding the 2 patients without $\mathrm{Hb}$ data, the average starting $\mathrm{Hb}$ levels in the post eGFR era was slightly higher than in the pre eGFR period, $(10.2 \pm 1.86 \mathrm{~g} / \mathrm{dl}$ vs. $9.89 \pm 2.26 \mathrm{~g} / \mathrm{dl})$, the difference did not however reach statistical significance $(\mathrm{p}=0.25)$.

$\mathrm{Hb}$ levels were compared in patients who were known to the renal service for less than 3 months prior to starting dialysis in the pre-eGFR vs. post eGFR era (Hb levels $9.24 \pm 1.92 \mathrm{~g} / \mathrm{dl}$ vs. $9.12 \pm 1.59 \mathrm{~g} / \mathrm{dl}, \mathrm{p}=0.78$ ). Similar comparisons were made for patients who had been adequately prepared prior to starting dialysis in the preeGFR compared to the post eGFR era (Hb levels $10.2 \pm$ $1.92 \mathrm{~g} / \mathrm{dl}$ vs. $11.0 \pm 1.71 \mathrm{~g} / \mathrm{dl}, \mathrm{p}=0.066)$.

$\mathrm{Hb}$ levels in patients who had been adequately prepared prior to starting dialysis was better in both the pre-eGFR era (Hb levels $10.2 \mathrm{~g} / \mathrm{dl}$ vs. $9.24 \mathrm{~g} / \mathrm{dl}, \mathrm{p}<0.05$ ) and the post eGFR era (Hb levels $11.0 \mathrm{~g} / \mathrm{dl}$ vs. $9.12 \mathrm{~g} / \mathrm{dl}$, $\mathrm{p}<0.001$ ) where the results were highly significant. Furthermore, out of the total population started on dialysis, the proportion of patients with Haemoglobin $(\mathrm{Hb})$ levels $\geq 11 \mathrm{~g} / \mathrm{dl}$ which was our minimum target $\mathrm{Hb}$ [4,5] increased from $25.4 \%$ to $41.1 \%$ (Table 1 ) in the post eGFR era.

We compared $\mathrm{Hb}$ levels between patients started on peritoneal dialysis (PD) and haemodialysis (HD) in the pre and post-eGFR era (Figure 1). Hb levels were consistently better in patients started on PD than on HD in both the pre $(10.4 \mathrm{~g} / \mathrm{dl}$ vs. $9.7 \mathrm{~g} / \mathrm{dl}, \mathrm{PD}$ vs. HD, $\mathrm{p}=0.14)$ and post (11.3 g/dl vs. $9.8 \mathrm{~g} / \mathrm{dl}$, PD vs. HD, $\mathrm{p}=0.004)$. The difference between $\mathrm{Hb}$ levels in people started on PD and HD however only reached statistical significance in the post-eGFR period.

Average $\mathrm{Hb}$ levels over the 2 year period were similar between male and female patients and between younger and older patients ( $\geq$ or $<70$ yrs) in both pre and post eGFR periods (data not shown).

$\mathrm{Hb}$ levels and time of referral to the renal services in the post eGFR period was examined in some detail (Figure 2). People known to the renal service for less than 1 month had the lowest Hb levels $(8.7 \mathrm{~g} / \mathrm{dl})$. Mean

Table 1. A comparison of haemoglobin levels at the time of starting initial renal replacement therapy in the period immediately before and after routine eGFR reporting.

\begin{tabular}{ccc}
\hline & Pre-eGFR (n= 79) & Post-eGFR (n=90) \\
\hline $\mathrm{Hb}<8 \mathrm{~g} / \mathrm{dl}$ & $7(8.9 \%)$ & $15(16.7 \%)$ \\
$\mathrm{Hb} 8.1-10.9 \mathrm{~g} / \mathrm{dl}$ & $52(65.8 \%)$ & $38(42.2 \%)$ \\
$\mathrm{Hb} 11-12 \mathrm{~g} / \mathrm{dl}$ & $13(16.5 \%)$ & $22(24.4 \%)$ \\
$\mathrm{Hb}>12 \mathrm{~g} / \mathrm{dl}$ & $7(8.9 \%)$ & $15(16.7 \%)$ \\
\hline
\end{tabular}

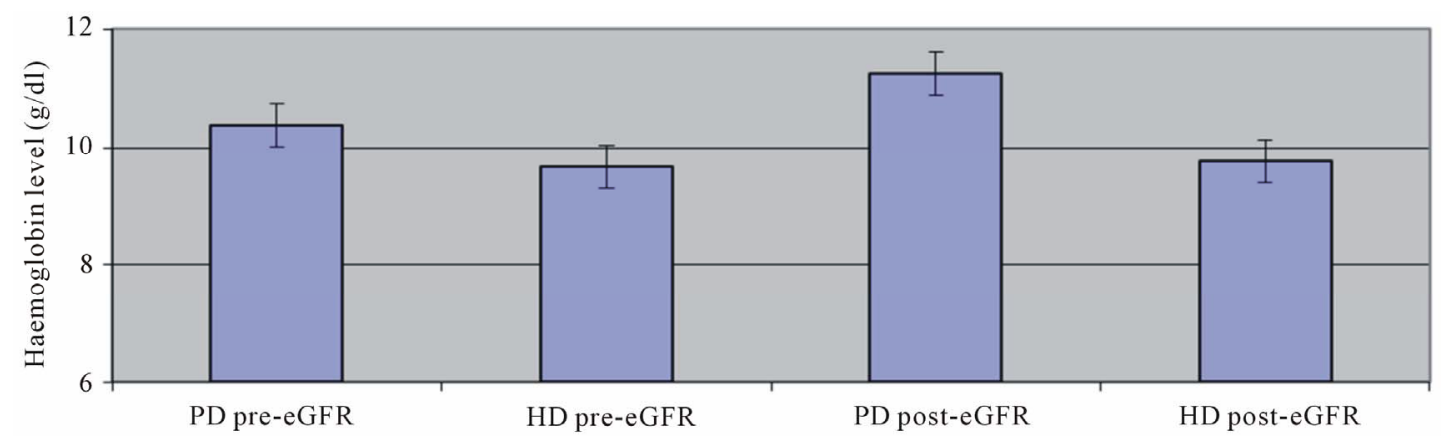

Figure 1. Haemoglobin levels just prior to initiating first haemodialysis or peritoneal dialysis treatments in patients with end stage kidney disease before and after routine eGFR reporting.

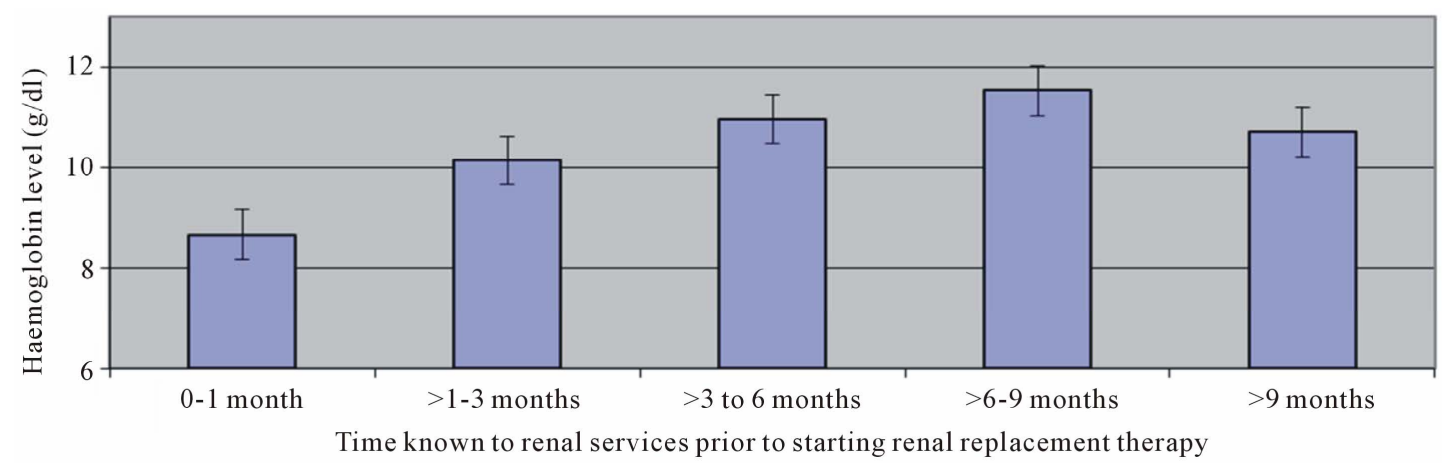

Figure 2. Comparison of haemoglobin levels in patients with end-stage kidney disease depending on time known to renal services just prior to initiating renal replacement therapy. 
$\mathrm{Hb}$ levels then gradually increased depending on time of referral, reaching a peak of $11.5 \mathrm{~g} / \mathrm{dl}$ in people referred $>6$ - 9 months prior to therapy. There was no statistical difference between initial $\mathrm{Hb}$ in people referred between $>6$ - 9 months and longer $(\mathrm{p}=0.23)$.

\section{DISCUSSION}

It is now widely accepted that serum creatinine does not accurately reflect renal excretory function and leads to a low awareness of people with chronic kidney disease [9].

The 4-variable MDRD eGFR gives a more reliable and practical estimate of renal function. The introduction of routine eGFR reporting in England alongside serum creatinine levels raises the possibility of earlier identification of people with kidney disease, with the potential for improvements in outcome [10]. Jain et al., 2009 and Noble et al., 2008, have shown that routine reporting of eGFR is associated with increased nephrology consults, predominantly in older and diabetic patients with stage 3 CKD. Richards et al., 2008, demonstrated a 7-fold month on month rise in nephrology referrals following institution of eGFR reporting which was only reversed by the introduction of a referral management service.

However, it is not clear whether this improved assessment of renal function and earlier recognition of people with kidney disease and the development of guidelines for the identification, management and referral of CKD in adults translates into practical improvements in disease management or outcomes.

This study attempted to partially address this question by investigating $\mathrm{Hb}$ levels at the time of starting RRT for the first time and comparing $\mathrm{Hb}$ values in the era before and after eGFR reporting started.

Anaemia is a common consequence of advanced kidney disease and is the result of decreased renal erythropoietin production, impaired iron utilization and iron deficiency. Iron supplementation and treatment with erythropoietin are used to optimise $\mathrm{Hb}$ levels to a target level of between $11-12 \mathrm{~g} / \mathrm{dl}$ in people with renal anaemia $[11,12]$.

Furthermore, anaemia has a significant impact on the quality of life of patients and warrants early recognition and treatment [13].

Our data shows that in both the pre and post eGFR era, approximately a third of people start RRT less than 3 months after initial contact with the renal services. We consider this to be probably inadequate time to permit optimal preparation for RRT.

For the purposes of this paper, we considered people known to the renal service for more than 3 months prior to starting RRT as probably having enough time for adequate preparation. We considered that a key assessment of the impact of eGFR reporting would be if $\mathrm{Hb}$ levels in these patients starting renal replacement therapy improved during after eGFR reporting started.

The average $\mathrm{Hb}$ levels in people starting dialysis for the first time was slightly better in the post eGFR period (9.89 vs. $10.2 \mathrm{~g} / \mathrm{dl}$ ) although this did not reach statistical significance. This was largely driven by an improvement in $\mathrm{Hb}$ levels on people started on dialysis for the first time who were known to the renal services for at least 3 months prior $(10.2 \mathrm{vs} .11 \mathrm{~g} / \mathrm{dl})$ where the difference just missed reaching statistical significance $(p=0.066)$.

$\mathrm{Hb}$ levels in people started on PD were superior to HD. Probably reflecting the fact that these people had typically been seen by the renal services for much longer than people starting on HD initially (sometimes for several years prior). While this difference missed statistical significance in the pre eGFR era $(p=0.14)$, the differences were highly significant in the post eGFR era $(\mathrm{p}=$ $0.004)$.

In both the pre and post eGFR periods, $\mathrm{Hb}$ levels were significantly better in people who had been in contact with the renal services for at least 3 months. The level of significance just attained statistical significance in the pre eGFR era $(p<0.05)$ and was highly significant in the post eGFR era $(\mathrm{p}<0.001)$.

Perhaps the single biggest change seen in the posteGFR period, was in the proportion of people starting dialysis for the first time with an $\mathrm{Hb}$ level greater than 11 $\mathrm{g} / \mathrm{dl}$. This increased by an additional $15 \%$ (from $25.4 \%$ to $41.1 \%$ ).

A number of recent publications (CHOIR, CREATE and TREAT studies) have addressed the use of ESAs in pre-dialysis patients. The CHOIR trial attained Hb levels of 12.6 and $11.3 \mathrm{~g} / \mathrm{dl}$ in 2 groups of CKD patients with intended $\mathrm{Hb}$ targets of 13.5 and $11.3 \mathrm{~g} / \mathrm{dl}$ respectively. This trial noted little evidence of cardiovascular benefit but increased non-significant trends to death, hospitalization for heart failure and a risk of progression of chronic kidney disease $[14,15]$. The CREATE trial achieved $\mathrm{Hb}$ levels of 11.5 vs. 13.5 using 603 randomly assigned patients and demonstrated similar risks of a composite of eight cardiovascular events at 3 years in patients with GFRs between 15 and $35 \mathrm{ml} / \mathrm{min} / 1.73 \mathrm{~m}^{2}$ [16]. The TREAT trial involved 4038 patients with diabetes, chronic kidney disease, and anaemia. They randomly assigned 2012 patients to darbepoetin alfa to achieve target $\mathrm{Hb}$ levels of $13 \mathrm{~g} / \mathrm{dl}$ and 2026 patients to placebo but with rescue treatment if $\mathrm{Hb}$ levels fell to $9 \mathrm{~g} / \mathrm{dl}$ or less. Death or a cardiovascular event occurred in 632 patients assigned to darbepoetin alfa and 602 patients assigned to placebo (hazard ratio for darbepoetin alfa vs. placebo, 1.05; 95\% confidence interval [CI], 0.94 to $1.17 ; \mathrm{p}=0.41$ ). They concluded that treatment did not reduce the risk of either of the two primary composite outcomes (death or a cardiovascular event or death or a renal event). There was 
however an increased risk of strokes [17]. This has raised significant questions about the appropriateness of initiation of erythropoiesis-stimulating agents (ESAs) in predialysis patients although it is widely accepted that severe anaemia is undesirable in patients with renal disease.

\section{CONCLUSIONS}

Our results suggest that there was a small trend towards an improvement in Hb levels on starting RRT for the first time in the post eGFR period compared to the pre eGFR period, although these differences did not reach statistical significance. Hb levels in people known to the renal services for at least 3 months prior to first RRT generally were generally higher. The proportion of people with $\mathrm{Hb}$ levels greater than $11 \mathrm{~g} / \mathrm{dl}$ increased substantially in the post-eGFR period.

Surprisingly the routine reporting of eGFR has so far not made a difference to the proportion of people starting RRT following late referral to the renal service. It remains to be seen whether or not this pattern will improve with time.

\section{AUTHORS CONTRIBUTIONS}

ST conceived of the study and performed the statistical analysis. Both ST and LC were involved in collecting data, checking for accuracy and in drafting the manuscript. All authors read and approved the final manuscript.

\section{REFERENCES}

[1] Stevens, L.A., Padala, S. and Levey, A.S. (2010) Advances in glomerular filtration rate-estimating equations. Current Opinion in Nephrology and Hypertension, 19, 298307. doi:10.1097/MNH.0b013e32833893e2

[2] Stevens, L.A., Zhang, Y. and Schmid, C.H. (2008) Evaluating the performance of equations for estimating glomerular filtration rate. Journal of Nephrology, 21, 797807.

[3] Schwartz, G.J., Haycock, G.B., Edelmann, C.M. and Spitzer, A. (1976) A simple estimate of glomerular filtration rate in children derived from body length and plasma creatinine. Pediatrics, 58, 259-263.

[4] Brion, L.P., Fleischman, A.R., McCarton, C. and Schwartz, G.J. (1986) A simple estimate of glomerular filtration rate in low birth weight infants during the first year of life: Noninvasive assessment of body composition and growth. Journal of Pediatics, 109, 698-707. doi:10.1016/S0022-3476(86)80245-1

[5] Levey, A.S., Greene, T., Kusek, J.W. and Beck, G.J. (2000) A simplified equation to predict glomerular filtration rate from serum creatinine. Journal of the American Society Nephrology, 11, 155A.

[6] Royal College of Physicians of London (2006) Chronic kidney disease in adults: UK guidelines for identification, management and referral. Royal College of Physicians, London.

[7] National Kidney Foundation (2006) K/DOQI clinical practice guidelines for chronic kidney disease: Evaluation, classification, and stratification. American Journal of Kidney Diseases, 39, A1. doi:10.1016/S0272-6386(02)70054-1

[8] Stevens, P.E. and O'Donoghue, D.J. (2009) The UK model for system redesign and chronic kidney disease services. Seminars in Nephrology, 29, 475-482. doi:10.1016/j.semnephrol.2009.06.004

[9] Ferris, M., Shoham, D.A., Pierre-Louis, M., Mandhelker, L., Detwiler, R.K. and Kshirsagar, A.V. (2009) High prevalence of unlabeled chronic kidney disease among inpatients at a tertiary-care hospital. The American Journal of the Medical Sciences, 337, 93-97. doi:10.1097/MAJ.0b013e318181288e

[10] Lamb, E.J. (2008) United Kingdom guidelines for chronic kidney disease. Scandinavian Journal of Clinical and Laboratory Investigation, 241, 16-22. doi:10.1080/00365510802144920

[11] Tagboto, S., Cropper, L., Mostafa, S., Turner J. and Pugh-Clark, K. (2008) Intravenous iron in chronic kidney disease: Haemoglobin change shortly after treatment of patients not on dialysis or erythropoietin. Journal of Renal Care, 34, 112-115. doi:10.1111/j.1755-6686.2008.00026.x

[12] Tagboto, S., Cropper, L., Turner, J. and Pugh-Clark, K. (2009) The efficacy of a single dose of intravenous ferric carboxymaltose (ferinject) on anaemia in a pre-dialysis population of chronic kidney disease patients. Journal of Renal Care, 35, 18-22. doi:10.1111/j.1755-6686.2009.00075.x

[13] Stevens, P.E., O'Donoghue, D.J. and Lameire, N.R. (2003) Anaemia in patients with diabetes: Unrecognised, undetected and untreated? Current Medical Research and Opinion, 19, 395-401. doi:10.1185/030079903125002036

[14] Singh, A.K., Szczech, L., Tang, K.L., Barnhart, H., Sapp, S., Wolfson, M., Reddan, D., CHOIR Investigators (2006) Correction of anemia with epoetin alfa in chronic kidney disease. New England Journal of Medicine, 355, 20852098. doi:10.1056/NEJMoa065485

[15] Inrig, J.K., Barnhart, H.X., Reddan, D., Patel, U.D., Sapp, S., Califf, R.M., Singh, A.K. and Szczech, L.A. (2012) Effect of hemoglobin target on progression of kidney disease: A secondary analysis of the CHOIR (Correction of hemoglobin and outcomes in renal insufficiency) trial. American Journal of Kidney Diseases.

[16] Drüeke, T.B., Locatelli, F., Clyne, N., Eckardt, K.U., Macdougall, I.C., Tsakiris, D., Burger, H.U., Scherhag, A., CREATE Investigators (2006) Normalization of hemoglobin level in patients with chronic kidney disease and anemia. New England Journal of Medicine, 355, 20712084. doi:10.1056/NEJMoa062276

[17] Pfeffer, M.A., Burdmann, E.A., Chen, C.Y., Cooper, M.E., De Zeeuw, D., Eckardt, K.U., Feyzi, J.M., Ivanovich, P., Kewalramani, R., Levey, A.S., Lewis, E.F., McGill, J.B., McMurray, J.J., Parfrey, P., Parving, H.H., Remuzzi, G., Singh, A.K., Solomon, S.D., Toto, R., TREAT Investiga- 
tors (2009) A trial of darbepoetin alfa in type 2 diabetes and chronic kidney disease. New England Journal of Me- dicine, 361, 2019-2032.

doi:10.1056/NEJMoa0907845 